\title{
Recovering fast and slow
}

\author{
Recovery efforts in the wake of COVID-19 must invest in energy systems that will prove cleaner and more resilient \\ in the face of future disasters.
}

\begin{abstract}
ike all systems of our civilization, energy systems have been profoundly impacted by the emergence and spread of COVID-19. After the virus first started overwhelming health systems in China, self-isolation and lockdown measures were introduced by the government leading to a decline in industrial production and electricity demand. The slowing economy reduced domestic electricity consumption as well, resulting in a precipitous decline in oil usage. This was exacerbated by oil use reduction in both transport within China and for intercontinental goods transport. This pattern has been repeating across the globe. Meanwhile, travel restrictions imposed by many nations have caused fuel consumption in air travel to fall drastically as well.
\end{abstract}

This reduction in oil consumption in particular and fossil fuel usage in general has led to a remarkable fall in carbon emissions ${ }^{1}$ and environmental pollution ${ }^{2}$. If one was to look only at carbon emissions, and ignore health and other indicators, the current situation appears to offer a glimpse at the kind of future that ambitious integrated energy-economy models have long been projecting. However, we know that this emission reduction cannot be celebrated because of the death toll and other health and economic impacts of COVID- 19.

In the context of modelling, analysis and planning for energy transition and human development, this offers a reminder that a focus on specific indicators such as carbon emissions or Gross Domestic Product (GDP) while muting other variables will never afford us a holistic view of welfare at the global scale. Future scenario research should be mindful of all the possibilities - good or bad - that can be represented by a certain set of parameter values in a model. For instance, the same emissions-GDP combination can arise from drastically different underlying conditions, as has been so forcefully demonstrated by the current drop in emissions.

Energy research will also have a lot to learn from the rapid and large-scale behavioural changes COVID-19 has forced on us. Many of these changes reduce energy demand. In time, the impacts of COVID-19 can afford energy social science researchers a chance to better understand the optimum ways to reduce energy footprints and what the best social and institutional means are to achieve this reduction. They may also help expose inequities that arise from such behaviour changes, such as the potential for increased energy poverty.

Right now, however, the priority is addressing the health crisis and saving lives, followed by restoring livelihoods and bringing economies back on track. Once the spread of COVID-19 is curtailed and industrial production and transportation start to ramp up to pre-contagion levels, energy demand will rise again. The path of least resistance for many producers and consumers at that stage would be to meet the restored demand with existing fossil energy infrastructure. In the transportation sector in particular the return of traffic to precontagion levels would increase oil and gas consumption and emissions. The situation in the industrial sector may not be much different. If low oil prices persist they will likely further help fossil fuel uptake.

Although emissions are down due to the reduction in fossil fuel consumption, the renewable energy industry is not benefitting. The demand for both solar and wind is expected to decrease and major Chinese solar panel producers have struggled to acquire certain raw materials and labour. The industry is already taking a hit because of instability in oil prices and disruption of the component supplychain $^{3}$. Once COVID-19 has been defeated, attracting investments and re-establishing the manufacturing and supply chains for wind and solar power will take much longer than turning up production at oil wells and restarting thermal power plant units.

It is thus important that economic recovery efforts and stimulus packages seek to avoid the massive potential emissions rebounds that would arise from a return to business as usual energy use. This must and can be done without further damaging people's well-being. In recovering from this disaster we must not forget that what makes COVID-19 so potent is not just the virus but certain structural features of our civilization. These vulnerabilities include healthcare systems without sufficient disaster resilience or slack and a global food, health and commodities supply-chain and just-in-time delivery systems. These systems depend on a taut fuel supply network that rests on a precarious global political consensus. Fossil fuel intensive industrial production and transportation and polluted urban centres also further exacerbate the health crises. Choices made in the energy system increase or decrease vulnerability in every system.

No recovery would be complete without at least an attempt to address these system vulnerabilities. From an energy systems perspective, this means ensuring that recovery and stimulus funds do not actively contribute to exacerbating health crises by increasing pollution. This means making hard but necessary choices about how recovery and stimulus funds are directed so as to build a more resilient and clean energy system. Renewable energy technologies that minimize pollution and emissions should receive some support. This is also important because renewable energy can provide immediate local jobs across manufacturing and installation.

In this way, the goals of recovery from this short emergency can tie into the goals of resilience against the long emergency of climate change. On the supply side, economic stimulus packages can support renewable technologies keeping us in line with climate ambitions and capitalizing on the emission reductions observed. On the demand side, efforts should be directed towards studying, formalizing and making permanent behavioural changes that reduce energy consumption without reducing productivity or welfare.

By the time it's over, this disaster will have introduced our civilization to a new way of living that leaves a much smaller energy footprint. While this new way may only be temporary, it would be unfortunate if we absorb no lessons from this crisis and insist on a return to pre-contagion business as usual.

Published online: 8 April 2020

https://doi.org/10.1038/s41560-020-0614-9

\footnotetext{
References

1. Myllyvirta, L. Analysis: Coronavirus temporarily reduced China’s $\mathrm{CO} 2$ emissions by a quarter. Carbon Brief https://www. carbonbrief.org/analysis-coronavirus-has-temporarily-reducedchinas-co2-emissions-by-a-quarter (2020).

2. Watts, J. \& Kommenda, N. Coronavirus pandemic leading to huge drop in air pollution. The Guardian https://www.theguardian. com/environment/2020/mar/23/coronavirus-pandemic-leadingto-huge-drop-in-air-pollution (2020).

3. Holder, M. \& Murray, J. Coronavirus dampens 2020 outlook for clean energy and electric vehicles. GreenBiz https://www.greenbiz. com/article/coronavirus-dampens-2020-outlook-clean-energyand-electric-vehicles (2020).
} 